\title{
Physicians' job satisfaction in their begin, mid and end career stage
}

\author{
Lodewijk J. Schmit Jongbloed, Johanna Schönrock-Adema, Jan C.C. Borleffs, Roy E. Stewart, Janke Cohen-Schotanus
} University Medical Centre Groningen, Netherlands

Received: September 15, 2016

Accepted: October 30, 2016

Online Published: November 11, 2016

DOI: $10.5430 /$ jha.v6n1p1

URL: http://dx.doi.org/10.5430/jha.v6n1p1

\begin{abstract}
Objective: To examine whether physicians differ in job satisfaction in different career stages, controlling for "gender", "specialty area" and "level of income".

Methods: Survey of three cohorts of physicians who started studying in 1972-75 $(\mathrm{n}=704), 1982 / 83(\mathrm{n}=301)$ and $1992 / 93$ $(n=296)$ at the University of Groningen. Physicians in the begin, mid and end career stage practiced for 10, 20 and 30 years respectively. Data were collected by telephonic interviews and written questionnaires. We selected 13 job satisfaction aspects which could be mapped unto Ostroff's taxonomy of organizational climate perceptions. Influences of gender, specialty area and level of income were taken into account.

Results: Physicians in begin, mid and end career stage differed on eight aspects. Taking into account gender, specialty area and level of income, differences between career stages were significant for three aspects: appreciation from support personnel, appreciation from patients and satisfaction with income. Specialty area was the most important covariate.

Conclusions: Physicians from different career stages differed in job satisfaction, but specialty area accounted to a large extent for these differences. We recommend taking into account physicians' career stage, gender and specialty area when studying physicians' job satisfaction.
\end{abstract}

Key Words: Job satisfaction, Physicians, Career stage, Age, Physician specialty

\section{INTRODUCTION}

This article focuses on job satisfaction in different career stages of physicians' working lives.

Job satisfaction can be defined as: "simply how people feel about their jobs and different aspects of their jobs", or more specifically as "the extent to which people like (satisfaction) or dislike (dissatisfaction) their jobs."[1] Although the main job and tasks of physicians usually stay the same during their career, a number of work-related characteristics may change during the years in practice. ${ }^{[2]}$ Consequently, the question arises whether and how physician job satisfaction differs between career stages. As satisfaction with job aspects can affect both the general attitude towards work and behavior in the workplace, it is surprising that - although physician job satisfaction has received much attention in the last decades up to now, little is known about physician job satisfaction in different career stages.

Physician job satisfaction appears to benefit both physicians and patients. It has crucial short- and long-term consequences for the physician's personal life and health. ${ }^{[3]}$ Strong negative correlations have been found between job satisfaction and burnout, lower self-esteem, anxiety, depression and

\footnotetext{
*Correspondence: Lodewijk J. Schmit Jongbloed; Email: info@schmitjongbloedadvies.nl; Address: University Medical Centre Groningen, Netherlands.
} 
physical health. ${ }^{[4]}$ Furthermore, job satisfaction leads to better quality of patient care, ${ }^{[2,3,5-7]}$ higher patient adherence to treatment, ${ }^{[8]}$ higher productivity ${ }^{[9]}$ and postponement of retirement. $^{[3]}$

The importance of life circumstances for job satisfaction is emphasized by stating that when individual's needs are met in the current situation, people will be satisfied. ${ }^{[10]}$ Life situation and needs may change as the individual moves through different career stages. ${ }^{[1]]}$ Therefore, job satisfaction should not be considered as unchanging and static. Prudence is called for in situations where initiatives are taken to improve job satisfaction because specific employment preferences and work-related needs in different career stages have to be acknowledged and considered. ${ }^{[12]}$ A better understanding of factors that influence job satisfaction in each career stage will give health care employers indications how to optimize physicians' job satisfaction and prevent early retirement. ${ }^{[13]}$ This is especially important in health care sectors that experience a shortage of physicians.

Although physician job satisfaction has received much attention in the last decades, evolution of job satisfaction aspects over the course of a physician's work-life has not been explored extensively and the outcomes diverge. Among surgeons, older age was associated with a greater satisfaction with overall career choice. ${ }^{[13]}$ However, others found a negative relation between age and satisfaction ${ }^{[14,15]}$ or no relationship. ${ }^{[16]}$ Still others found that younger and older working physicians - obstetricians and gynecologists - were most satisfied with their jobs, whereas those in between were less satisfied. ${ }^{[17-19]}$

Several possible explanations exist for these inconsistent results. Firstly, different definitions of job satisfaction were used. For example, a single-item global satisfaction rating was used or the job satisfaction instruments that were used were not based on a theoretical framework outlining the key concepts of job satisfaction. ${ }^{[13,15,18,19]}$ Secondly, some studies were limited to only female physicians ${ }^{[3,20]}$ or to specific specialties. ${ }^{[13,14,16,18]}$ Since males and females have been found to differ in their satisfaction with aspects of their jobs $^{[2,3,6,20,21]}$ and considering that the number of female physicians has increased in the past decades, ${ }^{[22]}$ job satisfaction differences found between physician in career stages may be distorted by gender. Thirdly, the focus on specific specialties in several studies may have distorted outcomes, since job satisfaction has been found to differ between specialties or specialty areas. ${ }^{[2,19,21-23]}$

In this study, we tried to avoid the described distortions. We differentiated between multiple aspects of job satisfaction, using Ostroff's taxonomy as our theoretical framework. ${ }^{[24,25]}$
This taxonomy distinguishes three domains of organizational climate perceptions: cognitive, affective and instrumental aspects of a job. The cognitive domain pertains to aspects like self-development and autonomy, the affective domain to interpersonal and social relations among workers, and the instrumental domain to getting things done in the organization. Our main goal was to analyze whether and how physicians differ in multiple job satisfaction aspects in three different career stages. We took gender and specialty area into account to avoid confounding influences from these variables. In addition, we took level of income into account, because this variable was found to be positively associated with job satisfaction. ${ }^{[2,3]}$ We formulated the following research questions:

(1) Do physicians who are in different career stages differ in their satisfaction with aspects of their job?

(2) Do differences in job satisfaction in different career stages persist after controlling for "gender", "specialty area" and "level of income"?

\section{METHOD}

\subsection{Sample and procedure}

We studied three cohorts of physicians who started their medical training and graduated at the University of Groningen. The older cohort of physicians started studying in $1972 / 73 / 74 / 75(n=704)$, the middle cohort in $1982 / 83$ $(\mathrm{n}=301)$ and the younger cohort in 1992/93 $(\mathrm{n}=296)$. When participating in the study, physicians in the younger cohort practiced for around 10 years, physicians in the middle cohort practiced for around 20 years and physicians from the older cohort for around 30 years. For physicians in the cohorts 1982/83 and 1992/93, telephone numbers were available from previous research. Both groups were approached for a strongly structured telephonic interview in 2009 and 2010 , respectively. The average interview time was $20 \mathrm{~min}-$ utes. For physicians in the cohort 1972/73/74/75 telephone numbers were not available. Therefore, we obtained the addresses and telephone numbers of these physicians from the Royal Dutch Medical Association (KNMG). As they appeared to be less willing to be interviewed by telephone, they were sent a postal questionnaire in 2011. For all cohorts, participation was voluntary and confidentiality was guaranteed. All respondents were informed about the study and gave their consent.

\subsection{Measures}

\section{Dependent variables: 13 aspects of job satisfaction}

To operationalize the theoretical framework for job satisfaction, we used Ostroff's taxonomy of organizational climate 
perceptions. ${ }^{[25]}$ This taxonomy seems suitable as a theoretical framework for measuring job satisfaction and has been valued as reflecting the integration of existing literature and, therefore, as a comprehensive classification. ${ }^{[24]}$ Ostroff distinguishes three broad categories of organizational climate perceptions, namely perceptions of the cognitive, affective and instrumental domain. The cognitive domain relates to the self and individuals' involvement in work activities (e.g. autonomy, growth, innovation, control and intrinsic rewards). The affective domain pertains to interpersonal and social relations (e.g. cooperation, participation, warmth and social rewards). The instrumental domain refers to getting things done in the organization (e.g. achievement, structure, hierarchy and extrinsic rewards).

Based on medical sociological literature, ${ }^{[2,23,26-28]}$ we selected the 13 most commonly mentioned aspects of physician job satisfaction and categorized these within Ostroff's domains. The cognitive domain relates to the self and individuals' involvement in work activities (e.g. autonomy, growth, innovation, control and intrinsic rewards). We operationalised this domain by selecting five aspects, mentioned to be important for physicians: opportunities for personal development, ${ }^{[23,28]}$ professional accomplishments, ${ }^{[26]}$ control over work planning, control over work content ${ }^{[26]}$ and administrative work. ${ }^{[26,28]}$ The affective domain pertains to interpersonal and social relations (e.g. cooperation, participation, warmth and social rewards). We operationalised this domain by selecting the aspects appreciation from colleagues, appreciation from supporting personnel, cooperation with colleagues and cooperation with supporting personnel. ${ }^{[23,26,28]}$ The instrumental domain refers to getting things done in the organization (e.g. achievement, structure, hierarchy and extrinsic rewards). We operationalised this domain by selecting the aspects cooperation with management, ${ }^{[26]}$ balance workprivate hours, ${ }^{[23,28]}$ appreciation from patients ${ }^{[26,28]}$ and income. ${ }^{[23,28]}$ We asked participants to score all 13 aspects on a 10 -point scale $(1=$ not satisfied at all, $10=$ extremely satisfied) as a 10-point scale is commonly used in Dutch schools and universities. Scores ranging from 0 to 5 equal "poor" to "insufficient", 6 equals "sufficient", 7 equals "good" and 8 to 10 equal "very good" to "excellent".

\section{Independent variables: Career stages}

Based on Super's model of multiple stages of career development, we defined three career stages: 0-15 years in practice $=$ establishment/begin career stage, $15-25$ years in practice $=$ maintenance $/$ mid-career stage and more than 25 years in practice $=$ disengagement/end career stage. ${ }^{[29,30]}$ In this article, we use the terms "begin", "mid" and "end" career stage.

\section{Covariates}

We included three covariates in our analyses: gender (male $=0$, female $=1$ ), specialty area and level of income. We distinguished three specialty areas: clinical specialists $(=1)$ working in a general or psychiatric hospital or a standalone treatment centre, general practitioners (GPs) $(=2)$ working in solo or group practices and other physicians (=3) working in nursing homes, medical insurance companies, pharmaceutical industries or management jobs. Level of income was measured by the physician's yearly gross income based on a full-time position.

\subsection{Data analysis}

An ANCOVA was conducted to analyze group differences between the three career stages with regard to the 13 aspects of job satisfaction (see Table 1). First, we included the three career stages in our analysis. Subsequently, we included the three covariates - gender, specialty area, and level of income - and finally, we added the two- and three-way interaction terms of the variables career stage, gender, and specialty area to the model (see Table 2). The significance level used was .05 .

All calculations were done with the statistical package SPSS for Windows (SPSS Inc., version 20, 2004) and SAS for Windows (SAS Institute Inc., version 9.2, 2008).

\section{RESUlts}

\subsection{Descriptives}

The begin, mid and end career stage samples consisted of 252 (response rate 85\%), $274(91 \%)$ and $330(47 \%)$ respondents respectively. The percentage of male physicians was $49 \%$ in the begin career stage group, $51 \%$ in the mid and $81 \%$ in the end career stage group. Physicians' specialty area was differently distributed over the career stages. The begin career group consisted of $65 \%$ clinical physicians, $21 \%$ GPs and $13 \%$ other physicians, the mid-career group of $48 \%$ clinical physicians, $22 \%$ GPs and $31 \%$ other physicians and the end career group of $40 \%$ clinical physicians, $28 \%$ GPs and $32 \%$ other physicians. During the end career stage, physicians were most satisfied with the appreciation of their patients. During the begin and mid-career stages, respondents were most satisfied with their own professional accomplishments. Physicians in all stages (begin to end career stage) were least satisfied with administrative work (see Table 1).

\subsection{Influence of career stage, gender, specialty area and income}

Preliminary analyses showed significant differences between career stages for eight of the 13 aspects of job satisfaction (see Table 1). After taking gender, specialty area and level 
of income into account, we found significant differences between career stages for three of the 13 aspects of job satisfaction (see Table 2). Physicians in their begin career stage were most satisfied with income and those in the end career stage least satisfied. Physicians in their mid-career stage were most satisfied with appreciation from support personnel and those in their end career stage least satisfied. Physicians in their begin career stage were least satisfied with appreciation from patients and those in their end career stage most satisfied.

Table 1. Job satisfaction differences between physicians in different career stages

\begin{tabular}{|c|c|c|c|c|c|c|}
\hline \multirow{3}{*}{ Career stage } & & Begin & Mid & End & \multirow{3}{*}{$\boldsymbol{F}$} & \multirow{3}{*}{$p$} \\
\hline & & \multicolumn{3}{|c|}{ Mean $(S D)$} & & \\
\hline & & $1992 / 93$ & 1982/83 & $1972 / 73 / 74 / 75$ & & \\
\hline \multirow{6}{*}{ Cognitive domain } & & & & & & \\
\hline & Opportunities for personal development & $7.59(1.03)$ & $7.29(1.05)$ & $7.53(1.34)$ & 4.75 & 009 \\
\hline & Own professional accomplishments & $7.82(0.85)$ & $7.79(0.84)$ & $7.99(0.92)$ & 4.47 & .012 \\
\hline & Control over work planning & $6.55(1.51)$ & $6.95(1.32)$ & $6.78(1.41)$ & 5.01 & .007 \\
\hline & Control over work content & $6.89(1.21)$ & $7.12(1.18)$ & $7.15(1.32)$ & 3.40 & .034 \\
\hline & Administrative work & $5.40(1.58)$ & $5.45(1.46)$ & $5.48(1.53)$ & 0.18 & .835 \\
\hline \multirow[t]{4}{*}{ Affective domain } & Appreciation from colleagues & $7.79(0.72)$ & $7.74(0.83)$ & $7.77(0.86)$ & 0.26 & .775 \\
\hline & Appreciation from support personnel & $7.60(0.79)$ & $7.69(0.71)$ & $7.25(1.10)$ & 18.54 & .000 \\
\hline & Cooperation with colleagues & $7.71(0.86)$ & $7.60(0.94)$ & $7.76(0.97)$ & 2.22 & .110 \\
\hline & Cooperation with support personnel & $7.38(0.72)$ & $7.40(0.79)$ & $7.36(0.97)$ & 0.14 & .868 \\
\hline \multirow[t]{4}{*}{ Instrumental domain } & Cooperation with management & $6.40(1.23)$ & $6.34(1.31)$ & $6.94(1.53)$ & 13.43 & .000 \\
\hline & Balance work - private life & $6.81(1.37)$ & $7.11(1.23)$ & $7.01(1.39)$ & 3.35 & .036 \\
\hline & Appreciation from patients & $7.61(0.65)$ & $7.74(0.75)$ & $8.00(0.88)$ & 16.97 & .000 \\
\hline & Satisfaction with income & $7.55(1.30)$ & $7.72(1.02)$ & $7.53(1.31)$ & 1.82 & .163 \\
\hline
\end{tabular}

Table 2. Job satisfaction differences between physicians in different career stages after taking into account gender, specialty area and level of income

\begin{tabular}{|c|c|c|c|c|c|c|c|c|}
\hline & & & Cs & G & Sp & $\begin{array}{l}\text { Level of } \\
\text { income }\end{array}$ & $\mathbf{C S} \times \mathbf{G}$ & $\mathbf{C S} \times \mathbf{S p}$ \\
\hline \multirow{10}{*}{$\begin{array}{l}\text { Cognitive } \\
\text { domain }\end{array}$} & \multirow{2}{*}{ Opportunities for personal development } & $F$ & 1.466 & 1.506 & 2.605 & 0.333 & 7.088 & \\
\hline & & $p$ & .232 & .220 & .075 & .564 & .001 & \\
\hline & \multirow{2}{*}{ Own professional accomplishments } & $F$ & .287 & 12.927 & 2.272 & 12.658 & & \\
\hline & & $p$ & .751 & .000 & .104 & .000 & & \\
\hline & \multirow{2}{*}{ Control over work planning } & $F$ & 2.017 & 3.312 & 2.678 & 0.327 & & 3.454 \\
\hline & & $p$ & .134 & .069 & .069 & .568 & & .008 \\
\hline & \multirow{2}{*}{ Control over work content } & $F$ & 0.226 & 2.385 & 3.553 & 3.156 & & 3.147 \\
\hline & & $p$ & .797 & .123 & .029 & .076 & & .014 \\
\hline & \multirow{2}{*}{ Administrative work } & $F$ & 0.749 & 0.169 & 14.318 & 0.103 & & \\
\hline & & $p$ & .473 & .682 & .000 & .749 & & \\
\hline \multirow{8}{*}{$\begin{array}{l}\text { Affective } \\
\text { domain }\end{array}$} & \multirow{2}{*}{ Appreciation from colleagues } & $F$ & 1.242 & 2.075 & 4.774 & 1.467 & & \\
\hline & & $p$ & .289 & .150 & .009 & .226 & & \\
\hline & \multirow{2}{*}{ Appreciation from support personnel } & $F$ & 22.798 & 4.419 & 8.591 & 2.633 & & \\
\hline & & $p$ & .000 & .036 & .000 & .105 & & \\
\hline & \multirow{2}{*}{ Cooperation with colleagues } & $F$ & 0.312 & 2.515 & 0.884 & 1.759 & & \\
\hline & & $p$ & .732 & .113 & .414 & .185 & & \\
\hline & \multirow{2}{*}{ Cooperation with support personnel } & $F$ & 2.758 & 9.099 & 3.400 & 0.114 & & 2.405 \\
\hline & & $p$ & .064 & .003 & .034 & .736 & & .048 \\
\hline \multirow{8}{*}{$\begin{array}{l}\text { Instrumental } \\
\text { domain }\end{array}$} & \multirow{2}{*}{ Cooperation with management } & $F$ & 1.151 & 1.181 & 6.186 & 2.831 & & \\
\hline & & $p$ & .317 & .277 & .002 & .093 & & \\
\hline & \multirow{2}{*}{ Balance work - private life } & $F$ & 0.215 & 0.782 & 5.125 & 1.309 & & \\
\hline & & $p$ & .807 & .377 & .006 & .271 & & \\
\hline & \multirow{2}{*}{ Appreciation from patients } & $F$ & 7.281 & 0.004 & 5.652 & 0.364 & & \\
\hline & & $p$ & .001 & .949 & .004 & .546 & & \\
\hline & \multirow{2}{*}{ Satisfaction with income } & $F$ & 5.370 & 0.562 & 0.270 & 63.906 & 3.345 & 2.398 \\
\hline & & $p$ & .005 & .454 & .764 & .000 & .036 & .049 \\
\hline
\end{tabular}

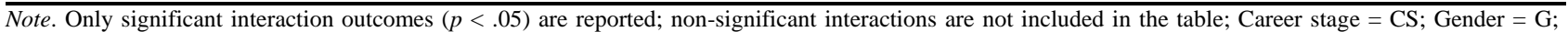
Speciality area $=\mathrm{Sp}$ 
We found main effects of the covariates gender, specialty area and level of income on several aspects of job satisfaction (see Table 2). Post hoc analysis showed that male physicians were more satisfied than female physicians with own professional accomplishments, appreciation from support personnel and cooperation with support personnel.

Post hoc analysis of the influence of specialty area on job satisfaction showed that the significant effects for specialty area were mainly attributable to the group "other physicians". These physicians were more satisfied with the aspects control over work content, administrative work, appreciation from colleagues, and balance work private life and less satisfied with appreciation from support personnel, cooperation with support personnel and appreciation from patients.

Level of income related positively with satisfaction with own professional accomplishments and satisfaction with income.

We also found two interaction effects between gender and career stage and four interaction effects between specialty area and career stage. Post hoc analysis revealed that female physicians in the begin career stage were more satisfied with opportunities for development, and male physicians were most satisfied with opportunities for development in the end career stage. During all career stages, male physicians were more satisfied with their income than females.

Four interactions were found between career stage and specialty area. Compared to younger colleagues, "clinical specialists" in the end career stage were more satisfied with control over work planning, control over work content, cooperation with support personnel, and income.

\section{Discussion}

We found that physicians in begin, mid and end career stages differ on eight of 13 aspects of job satisfaction. When gender, specialty area and level of income were taken into account, we only found significant differences between the career stages for three aspects of job satisfaction, namely appreciation from support personnel, appreciation from patients and satisfaction with income. Specialty area was the most important covariate.

Physicians in the end career stage were less satisfied with the aspects appreciation from support personnel than physicians in the other stages. A possible explanation for this outcome might be that a hierarchical culture was dominant at the time when these physicians were trained as residents. ${ }^{[26]}$ In such a culture, appreciation for the work of support personnel was not shown explicitly, which might reflect itself in a lower appreciation from support personnel. The higher satisfaction among older physicians with appreciation from

Published by Sciedu Press patients might be the result of a deep and broad experience with social facets of patient care and a long lasting relationship with their patients. This assumption is supported by previous research, which showed that physicians who value and maintain long-term patient relationships were in general more satisfied. ${ }^{[2]}$

Female physicians were less satisfied than male colleagues with their own professional accomplishments. This outcome is in line with studies discussing the unfavorable career opportunities for female physicians. ${ }^{[3,31]}$ However, female physicians place a high value on their careers. ${ }^{[32]}$ In this respect, our outcome that the satisfaction about opportunities for personal development is highest among females in the begin stage of their careers, is a hopeful sign, even more so, because the number of women entering medicine is still increasing. The lower satisfaction of female physicians in the mid and end career stage may be caused by the relative high percentage of part-timers in these groups. Part time work is associated with less challenging positions in which it is difficult to develop oneself further. ${ }^{[3,26]}$ The question is whether the women in our study who were in the beginning of their career, will face the same problems in the future or that they, indeed, belong to a new generation, which is more focused on opportunities for personal development in their career.

Clinical specialists, GP's and other physicians differ significantly on eight of the 13 studied aspects of job satisfaction. As the group of "other physicians" is a mixture of different (medical) professions and functions, we were cautious to make firm conclusions for this group. Clinical specialists are more satisfied about appreciation from support personnel and cooperation with support personnel compared to the other two groups. These outcomes may be explained from their daily intensive contact with nurse practitioners, physician assistants, operation room personnel et cetera. Clinical specialists are less satisfied with cooperation with management and balance work-private life. As in many western countries, clinical specialists work in independent specialty groups within the organizational construct of the hospital, where tensions between specialists and management often exist. As most GP's in the Netherlands are self-employed, they only work with management in a cooperation that organize night and weekend shifts for groups of 50-100 GP's. The management in these organizations is under control of the GP's themselves. This fact may explain the higher satisfaction of GP's with management.

The lower satisfaction of clinical specialists with the aspect balance work-private life may result from their long daily work hours and the frequent night and weekend shifts. GP's 
in the Netherlands work fewer hours, also because they have organized night and weekend shifts in groups of 50-100 GP's, which reduces the shift frequency considerably. The group of "other physicians" usually work regular hours without night and weekend shifts, working in nursing homes, pharmaceutical companies, insurance companies or as managers. The lower satisfaction of older GP's with cooperation with support personnel might reflect that, at the time they were in their begin career stage, GP's usually started in a solo practice, while GP's who graduated in the nineties or later, usually started in small or large group practices. ${ }^{[28]}$ As a result, the latter cohorts of GP's became more familiar with support personnel than their older colleagues.

The higher satisfaction of older clinical specialists with the aspects control over work planning and control over work content possibly reflects their increasing experience and confidence. Although this might be expected for GP's as well, their low satisfaction in the end career stage with both aspects might be the result of the increasing complexity of primary care over the last decades. Especially, for older GP's in solo practices, it may be difficult to adapt to these rapid changes. ${ }^{[33]}$ For older clinical specialists, this may be somewhat easier, as they are facilitated by medical support personnel.

GP's in all career stages are less satisfied than clinical specialists and other physicians with their control over work content and administrative work. Their lower satisfaction with both aspects may originate from the ever-increasing organizational complexity of health care, difficulties with insurers or bureaucratic tangles. ${ }^{[33]}$ Although these difficulties pertain to all specialty areas, clinical specialists and other physicians working in larger organizations can delegate these increasingly complex organizational and administrative tasks more easily to trained support personnel.

The higher the level of income, the more physicians are satisfied with their own professional accomplishments and income. The first finding is in line with previous research showing that a higher personal income leads to a better career satisfaction. ${ }^{[19]}$ It is remarkable, however, that physicians in the begin career stage were more satisfied about their income than physicians in the end stage. This difference cannot be explained by the level of income since the younger physicians make on average less money than the older ones.

A limitation of the study is the combination of subspecialties and groups of medical functions in the specialty areas "clinical specialists" and "other physicians". This combination was necessary in our study, because otherwise the numbers per subspecialty or group would have been too small for statistical analysis. It is, however, possible that subgroups of physicians within these groups also differ in job satisfaction. ${ }^{[19]}$ A second limitation is that all graduates attended the same medical school. However, as curricula for the eight medical schools in the Netherlands are very similar, our cohorts are likely to be representative for Dutch physicians in general. A third limitation is that the 1982/83 and 1992/93 cohorts were interviewed by telephone, while the cohort 1972/73/74/75 received the questionnaire by mail. The results for the cohorts could be biased as there could be differences in answers given in a telephonic interview compared to those provided on a written questionnaire. The written questionnaires resulted in a significant lower response (47\%), which may have distorted the results of the physicians in the end career stage. Another limitation of this study is that employment status and liability were not taken into account. Previous studies found no differences between self-employed and employed physicians. ${ }^{[2,34]}$ Liability is not a major issue among Dutch physicians. Finally, we limited our study to a cross-sectional study. Therefore, it is not clear whether differences between career stages are attributable to physicians' experience levels or to generational differences. Longitudinal research may add valuable insights about changes in job satisfaction over time.

Our research question, whether there are differences in job satisfaction between physicians in their begin, mid or end career stage, did not obtain a simple answer. Our results illustrate that job satisfaction is a complex phenomenon and may be even more complex than is suggested before. Scheurer and others already stated that job satisfaction of physicians could not be seen as a static variable but as "a dynamic interplay among the expectations and environments within which they work" "2] (p.560). This study adds to what is already known about physicians' job satisfaction as it shows that, next to environment (specialty area), also aspects like age group, gender and level of income belong to the list of variables influencing physicians' job satisfaction. This complexity of job satisfaction may explain why previous research on the relationship between job satisfaction and career stage or age led to inconsistent or even contradictory outcomes. In addition, our study supports the premise that it is important to differentiate between aspects of job satisfaction. Most studies on the relation between job satisfaction and age or career stage did not or insufficiently differentiate between job satisfaction aspects. Ostroff's taxonomy of three domains of organizational climate perceptions appeared to be a suitable framework to identify the distinct job satisfaction aspects. ${ }^{[25]}$ However, we did not find clear job satisfaction patterns per domain either. Further research might focus on the influence of context and personal circumstances on physician job satisfaction. 
Policy and practices to improve job satisfaction are often based on an unchanging and static perspective and usually result in a "one size fits all" approach, which is likely to be ineffective in terms of meeting the real needs of physicians. To increase physicians' job satisfaction, tailored interventions are needed taking into account career stage, gender and specialty area.

Our data can provide both healthcare employers and physicians with insights about the aspects that may be addressed to improve job satisfaction of male and female physicians in varying specialty areas in different career stages. For example, clinical specialists in their begin career stage, scoring relatively low on satisfaction with control over work planning and control over work content could profit from being mentored by experienced colleagues. ${ }^{[3]}$ General physicians in their end career stage could profit from training and support to handle the growing organizational complexity of health care. Considering the extremely low satisfaction with administrative tasks among all physicians - regardless of career stage, gender and specialty area - a reduction in the administrative complexity and duties of today's health care might increase the job satisfaction of all kinds of physicians.

In order to reduce physicians' administrative workload, some hospitals in the USA have introduced "medical scribes" at emergency departments and outpatient clinics. A "scribe" is an unlicensed person specially trained to chart clinicianpatient encounters in real time, from the beginning of the

\section{REFERENCES}

[1] Spector PE. Job satisfaction: application, assessment, causes, and consequences. In: Advanced topics in organization behavior. Thousand Oaks: SAGE Publications, Inc.; 1997. http://dx.doi.org /10.4135/9781452231549

[2] Scheurer D, McKean S, Miller J, et al. U.S. physician satisfaction: a systematic review. J Hosp Med. 2009; 4(9): 560-8. http: $/ /$ dx.doi.org/10.1002/jhm. 496

[3] Rizvi R, Raymer L, Kunik M, et al. Facets of career satisfaction for women physicians in the United States: a systematic review. Women Health. 2012 Jan; 52(4): 403-21. PMid: 22591235. http://dx.doi.org/10.1080/03630242.2012.674092

[4] Faragher EB, Cass M, Cooper CL. The relationship between job satisfaction and health: a meta-analysis. Occup Environ Med. 2005 Feb; 62(2): 105-12. PMid: 15657192. http://dx.doi.org/10. 1136/oem.2002.006734

[5] Scheepers RA, Boerebach BCM, Arah OA, et al. A systematic review of the impact of physicians' occupational well-being on the quality of patient care. Int J Behav Med. 2015; 22(6): 683-99. http://dx.doi.org/10.1007/s12529-015-9473-3

[6] Wallace JE, Lemaire JB, Ghali WA. Physician wellness: a missing quality indicator. Lancet [Internet]. 2009; 374(9702): 1714-21. encounter to its end, freeing up the physicians' time to focus on the patient. Research has shown that scribes improve both physician and patient satisfaction and patient-clinician interactions as well as productivity and revenues. ${ }^{[35]} \mathrm{We}$ advise hospitals and other health care organizations to start experiments with medical scribes to find out whether job satisfaction of physicians will increase.

\section{Conclusions}

We conclude that career stages are an important factor in physicians' job satisfaction. The complex relationships between career stages and different aspects of job satisfaction supports the idea that job satisfaction is a complex phenomenon. Not only is job satisfaction a multi-faceted construct, also factors like physician's specialty area and respondent gender influence job satisfaction. To increase job satisfaction of physicians, it is important not to use a "one size fits all" approach and to be aware of specific personal and organizational characteristics, such as the physician's career stage, gender and specialty area. Higher job satisfaction of physicians' is important as it may postpone retirement and improve quality of care.

\section{ACKNOWLEDGEMENTS}

We thank Laura Ramiro Pires Brammer for her help throughout the preparation of the manuscript.

\section{CONFlicts of InTEREST Disclosure}

The authors declare they have no conflicts of interest.
http://dx.doi.org/10.1016/S0140-6736 (09)61424-0

[7] Williams ES, Manwell LB, Konrad TR, et al. The relationship of organizational culture, stress, satisfaction, and burnout with physician-reported error and suboptimal patient care: results from the MEMO study. Health Care Manage Rev. 2007; 32(3): 203-12. PMid: 17666991. http://dx.doi.org/10.1097/01. HMR.0000 281626.28363.59

[8] DiMatteo MR, Sherbourne CD, Hays RD, et al. Physicians' characteristics influence patients' adherence to medical treatment: results from the Medical Outcomes Study. Heal Psychol. 1993 Mar; 12(2): 93-102. PMid: 8500445. http://dx.doi.org/10.1037/0278-6 133.12.2.93

[9] Judge TA, Thoresen CJ, Bono JE, et al. The job satisfaction-job performance relationship: a qualitative and quantitative review. Psychol Bull [Internet]. 2001; 127(3): 376-407. PMid: 11393302. http://dx.doi.org/10.1037/0033-2909.127.3.376

[10] Sousa-Poza A, Sousa-Poza AA. Well-being at work: a cross-national analysis of the levels and determinants of job satisfaction. J Socio Econ [Internet]. 2000 Nov; 29(6): 517-38. http://dx. doi.org/1 0.1016/S1053-5357(00) 00085-8

[11] Darcy C, McCarthy A, Hill J, et al. Work-life balance: one size fits all? An exploratory analysis of the differential effects of ca- 
reer stage. Eur Manag J [Internet]. 2012; 30(2): 111-20. http: //dx.doi.org/10.1016/j.emj.2011.11.001

[12] Bos JT, Donders NCGM, Bouwman-Brouwer KM, et al. Work characteristics and determinants of job satisfaction in four age groups: university employees' point of view. Int Arch Occup Environ Health [Internet]. 2009 Nov; 82(10): 1249-59. PMid: 19621236. http://dx.doi.org/10.1007/s00420-009-0451-4

[13] Shanafelt TD, Balch CM, Bechamps GJ, et al. Burnout and career satisfaction among American surgeons. Ann Surg [Internet] 2009; 250(3): 463-71. http://dx.doi.org/10.1097/sla.0b0 $13 \mathrm{e} 3181 \mathrm{ac} 4 \mathrm{dfd}$

[14] DeVoe J, Fryer GE, Hargraves JL, et al. Does career dissatisfaction affect the ability of family physicians to deliver high-quality patient care? J Fam Pract [Internet]. 2002; 51(3): 223-8. PMid: 11978232. Available from: http://www.ncbi.nlm.nih.gov/pubmed/1197 8232

[15] Sturm R. The impact of practice setting and financial incentives on career satisfaction and perceived practice limitations among surgeons. Am J Surg [Internet]. 2002 Mar; 183(3): 222-5. http: //dx.doi.org/10.1016/S0002-9610(02)00799-7

[16] Williams ES, Konrad TR, Linzer M, et al. Physician, practice, and patient characteristics related to primary care physician physical and mental health: results from the Physician Worklife Study. Health Serv Res [Internet]. 2002 Feb; 37(1): 119-41. http://dx.doi.o $\mathrm{rg} / 10.1111 / 1475-6773.00007$

[17] Haas JS, Puopolo AL, Burstin HR, et al. Differences in the professional satisfaction of general internists in academically affiliated practices in the greater Boston area. J Gen Intern Med. 1998; 13(2): 127-30. PMid: 9502374. http://dx.doi.org/10.1046/j.152 5-1497.1998.00030.x

[18] Kravitz RL, Leigh JP, Samuels SJ, et al. Tracking career satisfaction and perceptions of quality among US obstetricians and gynecologists. Obstet Gynecol [Internet]. 2003; 102(3): 463-70. http://dx.doi.org/10.1097/00006250-200309000-00007

[19] Leigh JP, Kravitz RL, Schembri M, et al. Physician career satisfaction across specialities. Arch Intern Med. 2002; 162: 1577-84. PMid: 12123400. http://dx.doi.org/10.1001/archinte.16 2.14.1577

[20] McMurray JE, Linzer M, Konrad TR, et al. The work lives of women physicians results from the physician work life study. The SGIM Career Satisfaction Study Group. J Gen Intern Med. 2000; 15(6): 372-80. PMid: 10886471.

[21] Keeton K, Fenner DE, Johnson TRB, et al. Predictors of physician career satisfaction, work-life balance, and burnout. Obstet Gynecol [Internet]. 2007; 109(4): 949-55. PMid: 17400859. http: //dx.doi.org/10.1097/01.AOG.0000258299.45979.37

[22] Davidson JM, Lambert TW, Goldacre MJ, et al. UK senior doctors' career destinations, job satisfaction, and future intentions: questionnaire surveys. Br Med J [Internet]. 2002; 325(7366): 685-6. Available from: http://www.pubmedcentral.nih.gov/articlerender. fcgi?artid=126656\&tool=pmcentrez\&
[23] Duffy RD, Richard GV. Physician job satisfaction across six major specialties. J Vocat Behav [Internet]. 2006; 68(3): 548-59. Available from: http://linkinghub.elsevier.com/retrieve/pii/

[24] Carr JZ, Schmidt AM, Ford JK, et al. Climate perceptions matter: a meta-analytic path analysis relating molar climate, cognitive and affective states, and individual level work outcomes. J Appl Psychol. 2003; 88(4): 605-19. PMid: 12940402. http://dx.doi.org/10. 1037/0021-9010.88.4.605

[25] Ostroff $\mathrm{C}$. The effects of climate and personal influences on individual behavior and attitudes in organizations. Organ Behav Hum Decis Process. 1993; 56(1): 56-90. http://dx.doi.org/10.1006/obh d. 1993.1045

[26] McMurray JE, Heiligers PJM, Shugerman RP, et al. Part-time medical practice: where is it headed? Am J Med [Internet]. 2005; 118(1): 87-92. PMid: 15639215. http://dx.doi.org/10.1016/j.amj med.2004.11.005

[27] SHM Career Satisfaction Task Force. A challenge for a new specialty: a white paper on hospitalist career satisfaction [Internet] US; 2006. Available from: http: http://www.hospitalmedici ne.org/AM/Template.cfm?Section=White_Papers\&Templ ate $=/ \mathrm{CM} /$ ContentDisplay. $\mathrm{cfm} \&$ Content $I D=14631$

[28] van Ham I, Verhoeven AAH, Groenier KH, et al. Job satisfaction among general practitioners: a systematic literature review. Eur $\mathbf{J}$ Gen Pract [Internet]. 2006 Jan; 12(4): 174-80. PMid: 17127604. http://dx.doi.org/10.1080/13814780600994376

[29] Super DE. A life-span, life-space approach to career development. Joural Vocat Behav. 1980; 16(3): 282-98. http://dx.doi.org/1 $0.1016 / 0001-8791(80) 90056-1$

[30] Ng TWH, Feldman DC. Organizational embeddedness and occupational embeddedness across career stages. J Vocat Behav [Internet] 2007 Apr; 70(2): 336-51. http://dx.doi.org/10.1016/j.jvb .2006 .10 .002

[31] Buddeberg-Fischer B, Stamm M, Buddeberg C, et al. The impact of gender and parenthood on physicians' careers - professional and personal situation seven years after graduation. BMC Health Serv Res [Internet]. 2010 Jan; 10(1): 40-50. PMid: 20167075. http://dx.doi.org/10.1186/1472-6963-10-40

[32] Clem KJ, Promes SB, Glickman SW, et al. Factors enhancing career satisfaction among female emergency physicians. Ann Emerg Med [Internet]. 2008 Jun; 51(6): 723-8, e8. Available from: http: //www.ncbi.nlm.nih.gov/pubmed/18342991

[33] Zuger A. Dissatisfaction with medical practice. N Engl J Med. 2004; 350(1): 69-75. http://dx.doi.org/10.1056/NEJMsr031703

[34] Heath EL. Career satisfaction of physicians employed by health systems [dissertation]. [Birmingham (AL)]: University of Alabama; 2012.

[35] Shultz CG, Holmstrom HL. The use of medical scribes in health care settings: a systematic review and future directions. J Am Board Fam Med [Internet]. 2015; 28(3): 371-81. PMid: 25957370 http://dx.doi.org/10.3122/jabfm.2015.03.140224 